\title{
Research on Evaluation of Operational Efficiency of Civil Aviation Flight
}

\author{
Fengfeng Liu \\ Operation Monitoring Center, Civil Aviation Administration of China, Beijing 100710, China. \\ liufengfeng555@126.com
}

\begin{abstract}
In order to reasonably evaluate the flight operation efficiency, the civil aviation flight operation efficiency evaluation index system is established from five aspects: quality and safety, environment, transportation efficiency, capacity resources and economic benefits. In view of the fact that the flight operation efficiency index weight is not fixed, the catastrophe progression method is introduced into such evaluation. Using the actual operational data of China's civil aviation, the model is used for evaluation, and the evaluation results obtained are basically consistent with the actual development of China's civil aviation industry.
\end{abstract}

Keywords: civil aviation flight; operating efficiency; index system; catastrophe progression.

\section{Introduction}

With the rapid development of China's national economy, air transport has made great progress as one of the important ways of transportation. In 2017, the total turnover of China's civil aviation industry was 108.038 billion tons, an increase of $12.6 \%$ over the previous year; the passenger turnover was 951.304 billion person-kilometers, an increase of $13.5 \%$ over the previous year; the passenger traffic volume was 55.56 million person-times, an increase over the previous year. 13.0\% [1]. The growth of these transportation data also indicates that China's air traffic flow has increased significantly year by year, and higher requirements must be imposed on air traffic control units, air operators and airport operating systems. Air traffic congestion and the continuous increase in flight delays have not been effectively mitigated by a single means such as increasing routes, gradually liberalizing airspace and refining altitude levels. Therefore, it is necessary to establish a scientific and effective evaluation index system for civil aviation flight operation efficiency, analyze the operational efficiency according to the actual operational data of the industry, and find out the key factors affecting the operational efficiency, and provide improvement directions for the organization optimization and resource allocation of the civil aviation system. In this way, the flight operation efficiency is improved.

In the field of transportation, many scholars have also carried out research on operational efficiency evaluation. These studies included operational efficiency assessments of various modes of transportation. In terms of urban rail transit efficiency, Guihaire et al. [2] took the route schedule as the research object, and considered the operation of the entire rail transit system, and gave the schedule of the route that can achieve the best transfer efficiency. Navarrete et al. [3] analyzed the subway system in Santiago, Chile, and came up with factors that affect its operational efficiency. Zhang Hao et al [4] evaluated the transportation efficiency of urban rail transit in China based on data envelopment analysis (DEA) and Tobin model (Tobit) and analyzed its influencing factors. In terms of road transportation, the operational efficiency is mainly reflected by road congestion. Daniela Bremmer et al. proposed the concept of time reliability, collected corresponding data for analysis, and proposed a new principle of congestion evaluation [5]. Long Kejun used the "multiple input and multiple output" system analysis and evaluation, and established the urban road network operation efficiency evaluation index system, including six "input" categories and three "output" indicators [6]. Qin Jin et al. proposed a quantitative evaluation method for the operational efficiency of road traffic network, which can reflect the impact of traffic demand, road segment flow, and travel negative utility on traffic network efficiency [7]. Wang Gu et al. established a monitoring method for highway traffic efficiency, including the measurement of operational efficiency during different operational periods and the identification of abnormal conditions occurring during operation [8]. In terms of railway 
transportation, Gao Ying divided the production process of railway transportation enterprises into vehicle maintenance and operation sub-processes, established the efficiency evaluation index system of railway transportation enterprises, and constructed a two-stage network DEA model [9]. Tan Yushun and others divided the railway transportation process into railway passenger transportation service process, freight service process and transportation operation process, and proposed a kind of network DEA measurement model [10]. In terms of civil aviation transportation, Don Harris used the social technology system method to analyze how to improve the efficiency of aviation operations from the perspective of human factors, thus proposed to change the slope of the airport; select the crew; provide direct flights; increase the cab Four ways to improve operational efficiency, such as automation equipment [11]. Based on the track data obtained by ADS-B, Ma Wei analyzed the vertical section running efficiency index algorithm of the flight descent phase and evaluated the operational efficiency of the flight terminal area in China [12].

\section{An Evaluation Index System}

The analysis of flight operation efficiency is different from the analysis of civil aviation operation system. It is necessary to establish its efficiency evaluation index system based on the characteristics of flight operation. The Federal Aviation Administration (FAA) established the ATM's Working Together Team in the Air Traffic Organization (ATO). The ATT team has macroscopically divided the efficiency of US flight operations into seven aspects: safety, security, system operational performance, operating costs, system update costs, collaborative communication navigation, and environmental efficiency. The European Union established the Performance Review Commission (RPC), which defines flight operating efficiency as the following five aspects: safety, traffic capacity, operational efficiency, environment, and economic benefits. Combined with the operational characteristics, organizational structure and national policies of China's civil aviation industry, the flight efficiency of civil aviation flights is divided into five parts: quality and safety, environment, transportation efficiency, capacity and resources, economic benefits. The specific index system is shown in Table 1.

Table 1. Civil aviation flight operation efficiency index system

\begin{tabular}{|c|c|}
\hline secondary indicator & three-level indicator \\
\hline quality and safety (B1) & $\begin{array}{l}\text { air transportation serious incident rate per } 10 \text { thousand flight hours }(\mathrm{C} 1) \\
\text { air consumer complaint events rate per } 10 \text { thousand people }(\mathrm{C} 2)\end{array}$ \\
\hline environment (B2) & fuel consumption per flight kilometer (kilogram / sortie $•$ kilometre $)(\mathrm{C} 3)$ \\
\hline & carbon dioxide emissions per flight kilometer (ton / sortie $\bullet$ hour)(C4) \\
\hline $\begin{array}{l}\text { transportation efficiency } \\
\text { (B3) }\end{array}$ & average flight normal rate (C5) \\
\hline & $\begin{array}{l}\text { passenger load factor of scheduled flight (C6) } \\
\text { cargo load factor of scheduled flight (C7) }\end{array}$ \\
\hline $\begin{array}{l}\text { capacity and } \\
\text { resources(B4) }\end{array}$ & total mileage of the route $(10,000$ kilometers $)(\mathrm{C} 8)$ \\
\hline economic benefits(B5) & $\begin{array}{l}\text { Investment in civil aviation capital construction and technological transformation } \\
\qquad(100 \text { million yuan) (C9) } \\
\text { annual total operating income of the whole industry (100 million yuan) (C10) }\end{array}$ \\
\hline
\end{tabular}

\section{The Evaluation Method}

The evaluation of flight operation efficiency is also a comprehensive evaluation. The main task is to establish an evaluation index system and determine the weight of each indicator. Common methods for determining weights include expert survey method (Delphi method) and analytic hierarchy process (AHP), which are susceptible to subjective factors. The catastrophe progression method does not need to determine the weight before evaluation, but only needs to determine the order of 
importance of each indicator. The catastrophe progression method has been widely used in comprehensive evaluation. This paper intends to use this method to evaluate the efficiency of civil aviation flight operation and explain its effectiveness and applicability. Common mutation models are shown in Table 1.

Table 2. Common catastrophe models

\begin{tabular}{|c|c|c|c|c|}
\hline Model type & $\begin{array}{l}\text { Control } \\
\text { variables }\end{array}$ & $\begin{array}{c}\text { State } \\
\text { variables }\end{array}$ & Potential function & Normalized formula \\
\hline $\begin{array}{l}\text { Cusp } \\
\text { catastrophe }\end{array}$ & $a, b$ & $\mathrm{x}$ & $V(x)=x^{4}+a x^{2}+b x$ & $x_{a}=\sqrt{|\mathrm{a}|}, x_{b}=\sqrt[3]{|\mathrm{b}|}$ \\
\hline $\begin{array}{l}\text { swallowtail } \\
\text { catastrophe }\end{array}$ & $a, b, c$ & $\mathrm{x}$ & $V(x)=x^{5}+a x^{3}+b x^{2}+c x$ & $x_{a}=\sqrt{|\mathrm{a}|}, x_{b}=\sqrt[3]{|\mathrm{b}|}, x_{c}=\sqrt[4]{|\mathrm{c}|}$ \\
\hline $\begin{array}{l}\text { butterfly } \\
\text { catastrophe }\end{array}$ & $\mathrm{a}, \mathrm{b}, \mathrm{c}, \mathrm{d}$ & $\mathrm{x}$ & $V(x)=x^{6}+a x^{4}+b x^{3}+c x^{2}+d x$ & $x_{a}=\sqrt{|\mathrm{a}|}, x_{b}=\sqrt[3]{|\mathrm{b}|}, x_{c}=\sqrt[4]{|\mathrm{c}|}, x_{d}=\sqrt[5]{|\mathrm{d}|}$ \\
\hline $\begin{array}{l}\text { wigwan } \\
\text { catastrophe }\end{array}$ & $a, b, c, d, e$ & $\mathrm{x}$ & $\begin{array}{c}V(x)= \\
x^{7}+a x^{5}+b x^{4}+c x^{3}+d x^{2}+e x\end{array}$ & $\begin{array}{c}x_{a}=\sqrt{|\mathrm{a}|}, x_{b}=\sqrt[3]{|\mathrm{b}|}, x_{c}=\sqrt[4]{|\mathrm{c}|}, x_{d}=\sqrt[5]{|\mathrm{d}|}, \\
x_{e}=\sqrt[6]{|\mathrm{e}|}\end{array}$ \\
\hline
\end{tabular}

\section{Case Analysis}

According to the records of the official website of the Civil Aviation Administration of China, we can easily find statistical bulletins on the development of civil aviation industry in each year. We select the data from 2013 to 2017 for analysis. From the development statistics bulletin, we can find the data of the indicator value or the original value used to calculate the indicator value. For the obtained index values, standardization processing is required. Let $x_{i}$ be the value of the indicator and $x_{i}{ }^{\prime}$ be its normalized value. The quality and safety indicators and the environment indicators are all reverse indicators, the standardized formula of the index values is (1). The transportation efficiency, capacity and resources, economic benefits indicators are positive indicators, and the standardized formula of the index values is (2).

$$
\begin{gathered}
x_{i}^{\prime}=\frac{x_{\max (i)}-x_{i}}{x_{\max (i)}-x_{\min (i)}} \\
x_{i}^{\prime}=\frac{x_{i}-x_{\min (i)}}{x_{\max (i)}-x_{\min (i)}}
\end{gathered}
$$

$x_{i}$ is the raw data of the underlying indicator; $x_{i}{ }^{\prime}$ is the dimensionless calculation; $x_{\max (i)}$ and $x_{\min (i)}$ are the critical values of the membership function.

Before a formal evaluation, it is necessary to determine the order in which the indicators at each level are ranked. We rank the secondary indicators in order of transportation efficiency, quality and safety, economic efficiency, environment, capacity and resources. Obviously, the secondary indicators and the primary indicators constitute the wigwan catastrophe. The transport efficiency and its corresponding three-level indicators constitute a swallowtail catastrophe. The quality and safety, economic benefits, environment, capacity and resources and their corresponding three-level indicators constitute a cusp catastrophe. The corresponding order and calculation formula of the indicator are as follows.

$$
x_{B 1}=\left(\sqrt{x_{C 1}}+\sqrt[3]{x_{C 2}}+\right) / 2
$$




$$
\begin{aligned}
& x_{B 2}=\left(\sqrt{x_{C 3}}+\sqrt[3]{x_{C 4}}\right) / 2 \\
& x_{B 3}=\left(\sqrt{x_{C 5}}+\sqrt[3]{x_{C 6}}+\sqrt[4]{x_{C 7}}\right) / 3 \\
& x_{B 4}=\left(\sqrt{x_{C 8}}+\sqrt[3]{x_{C 9}}\right) / 2 \\
& x_{B 5}=\left(\sqrt{x_{C 10}}+\sqrt[3]{x_{C 11}}\right) / 2 \\
& x_{A}=\left(\sqrt{x_{B 3}}+\sqrt[3]{x_{B 1}}+\sqrt[4]{x_{B 5}}+\sqrt[5]{x_{B 2}}+\sqrt[6]{x_{B 4}}\right) / 5
\end{aligned}
$$

After standardizing the data values of the indicators for 2013-2017, they will be brought into the equations (3) to (8) to obtain the evaluation values of the flight operating efficiency of China's civil aviation, as shown in Table 3.

Table 3. Evaluation value of China's civil aviation flight operation efficiency from 2013 to 2017

\begin{tabular}{cccccc}
\hline year & 2013 & 2014 & 2015 & 2016 & 2017 \\
\hline Evaluation value & 0.93873 & 0.94636 & 0.95731 & 0.96135 & 0.96932 \\
\hline
\end{tabular}

It can be seen from the above evaluation values that the difference between the annual values is not obvious, which is due to the phenomenon caused by the normalization formula. This phenomenon makes the comparison and analysis of annual operational efficiency difficult. Therefore, it is necessary to determine the set of reviews of the operational efficiency of civil aviation flights and the range of their corresponding membership values. Refer to other industry evaluation experience and the actual situation of the civil aviation industry, the flight operation efficiency is divided into four levels: IV (excellent), III (good), II (general), and I (poor). The specific results are shown in Table 4.

Table 4. Grade standard for safety performance evaluation

\begin{tabular}{ccccc}
\hline Grade standard & I (poor) & II (general) & III (good) & $\begin{array}{c}\text { IV } \\
\text { (excellent) }\end{array}$ \\
\hline $\begin{array}{c}\text { The range of corresponding } \\
\text { membership values }\end{array}$ & $0 \sim 0.4$ & $>0.4 \sim 0.6$ & $>0.6 \sim 0.8$ & $>0.8 \sim 1$ \\
$\begin{array}{c}\text { The range of total membership } \\
\text { degrees }\end{array}$ & $0 \sim 0.90125$ & $0.90125 \sim 0.94330$ & $0.94330 \sim 0.97470$ & $0.97470 \sim 1$ \\
\hline
\end{tabular}

\section{Conclusion}

Comparing Tables 3 and 4, we can get the 2013-2017 China Civil Aviation Flight Operation Efficiency Rating. By comparison, it is found that the flight operation efficiency obtained by using the above evaluation model is consistent with the actual situation. This shows that the index system and evaluation method of this paper have certain validity and applicability.

\section{References}

[1]. 2017 Civil Aviation Industry Development Statistics Bulletin. Information on: http:// www. caac. gov.cn/XXGK/XXGK/TJSJ/201805/t20180521_188131.html. 
[2]. Guihaire V, Hao J K. Improving Timetable Quality in Scheduled Transit Networks. [C]// International Conference on Industrial Engineering and Other Applications of Applied Intelligent Systems. Springer-Verlag, 2010:21-30.

[3]. Navarrete F J, Ortúzar J D D. Subjective valuation of the transit transfer experience: The case of Santiago de Chile[J]. Transport Policy, 2013, 25(1):138-147.

[4]. ZHANG Hao, YOU Jianxin. An Empirical Study of Transport Efficiency of Urban Rail Transit Based on Data Envelopment Analysis and Tobit Model[J]. Journal of Tongji University (Natural Science), 2018.

[5]. Bremmer D, Campbell M. RESEARCH PAYS OFF. Sharing Knowledge, Improving Decisions, and Establishing Accountability. Comparative Performance Measurement Demonstrates Benefits[J]. Tr News, 2014.

[6]. LONG K J, Lei L, XIAO X L, et al. Operating efficiency evaluation for urban road network [J]. Journal of Central South University (Science and Technology), 2013(s1):430-L435.

[7]. Jin Q, Feng S, Deng L B, et al. Quantitative evaluation method for road transportation network efficiency and its application[J]. Journal of Jilin University, 2010.

[8]. Wang G, Guo X, Jiang Y, et al. Research on Efficiency Monitoring Methods of Freeway Operation[J]. Journal of Highway \& Transportation Research \& Development, 2010.

[9]. Gao Y, Wei-Dong L I, You X Y. Research on the Efficiency Evaluation of China's Railway Transport Enterprises with Network DEA[J]. China Soft Science, 2011.

[10]. TAN Yushun, CHEN Senfa. Research on the efficiency of China's rail transport- - A range adjusted measure of network DEA perspective [J]. Journal of Railway Science and Engineering,2015(5):1219-1226.

[11]. Don Harris. The Influence of Human Factors on Operational Efficiency[J]. Aircraft Engineering and Aerospace Technology, 2006,11(78):1-25.

[12]. MA Ling-ling, YANG Cheng-kai. Quantitative Research on Vertical Flight Efficiency During Descent[J]. Aeronautical Computing Technique, 2018. 